\title{
Acessibilidade para pessoas com deficiência visual como fator de inclusão digital
}

\author{
Letícia Ramos Reinaldi' \\ Cláudio Rosa de Camargo Júnior ${ }^{2}$ \\ Angélica Toffano Seidel Calazans ${ }^{3}$
}

\section{Resumo}

O objetivo da pesquisa foi identificar soluções que promovam a maior inclusão digital para pessoas com deficiência visual, considerando suas necessidades atuais e as iniciativas nacionais e internacionais existentes. A pesquisa qualitativa, realizada por meio de entrevistas com deficientes visuais e videntes que trabalham com os deficientes visuais, possibilitou a triangulação dos resultados. O estudo possibilitou constatar que as iniciativas para aumentar a acessibilidade dos deficientes visuais ao meio digital estão fundamentalmente apoiadas no W3C e nas iniciativas de estudos liderados por universidades na busca de novas soluções. A pesquisa demonstrou que, apesar das iniciativas existentes, a inclusão digital dos deficientes visuais está longe do ideal e que a falta de iniciativas efetivas para aumentar a empregabilidade da tecnologia a esses usuários é uma realidade e é um dos reflexos da sociedade construída com base em indivíduos sem deficiência.

Palavras-chave: Inclusão digital. Deficiência visual. Analfabetismo digital. Acessibilidade. Ferramentas de acessibilidade. Inclusão social. Pessoa com deficiência

\section{Introdução}

As questões de acessibilidade e inclusão digital, com foco em pessoas com deficiência visual, têm sido muito discutidas e estudadas. É interessante lembrar-

1 Graduada em Analise e Desenvolvimento de Sistemas - UniCEUB e Graduada em Engenharia Agronômica - UNB.

2 Graduado em Analise e Desenvolvimento de Sistemas - UniCEUB.

3 Doutora em Ciência da Informação, docente do Curso de Análise de Sistemas do UniCEUB e Consultor TI da Caixa Econômica Federal. 
-se da grande segregação sofrida ao longo da história por indivíduos que nascem com algum tipo de deficiência, seja ela qual for. Hoje, apesar de o deficiente ser mais aceito pela sociedade, ele ainda é, muitas vezes, excluído por preconceitos ou até mesmo por falta de tecnologias que facilitem sua convivência com os demais cidadãos, dificultando a integração entre os deficientes e a população em geral.

Kose (2004) destaca que, em muitos países, as políticas de inclusão se mostram eficientes, sendo socialmente aceitas. No Brasil, segundo Carvalho (2004), a inclusão de jovens com deficiência física no trabalho ou nos ambientes escolares só será efetiva se tais locais forem abertos às diferenças e se tiver como condição básica espaços físicos e tecnológicos livres de barreiras físicas e de informação. A presença do indivíduo portador de deficiência, no mundo atual, passa pela penetração e materialização dos recursos da informática, agindo sobre as atividades em geral e modificando os instrumentos de percepção e ação (CAMARGO, 1994).

Um dos aspectos importantes na inclusão de um indivíduo portador de deficiência é a inclusão digital. O conceito de inclusão digital envolve o acesso de todas as pessoas, deficientes ou não, ao mundo virtual. E, se o processo de inclusão do indivíduo portador de deficiência é complexo, o processo de sua inclusão no mundo digital apresenta uma série de dificuldades e obstáculos.

Considerando essa complexidade do processo de inclusão digital com relação ao indivíduo portador de deficiência visual, o presente artigo tem como objetivo identificar algumas barreiras e dificultadores existentes na TI, de forma a possibilitar a implementação de ações para a melhoria da inclusão social. A seguir, apresentam-se a justificativa da pesquisa, os objetivos gerais e específicos (seção 2) e as informações sucintas sobre o portador de deficiência e a inclusão social (seção 3). Na seção 4, abordaremos os conceitos de acessibilidade com foco nos deficientes visuais, e na seção 5, será apresentada a metodologia de pesquisa utilizada no levantamento de informações junto a deficientes visuais e videntes, a fim de enumerar as necessidades e dificuldades para a inclusão digital dos deficientes. Os resultados da aplicação do instrumento de coleta estão demonstrados seção 6, e na seção 7 , a conclusão do trabalho. 


\section{Justificativa da pesquisa, objetivos gerais e específicos}

O conceito de inclusão digital envolve oferecer acesso a todas as pessoas que não estejam conectadas ao mundo virtual e também a ensiná-las a utilizar a internet para resolver os problemas do dia a dia (PRESSIONTT, 2003). Segundo Amaral (2003), menos de 1\% da população mundial tem algum tipo de acesso à internet $\mathrm{e}$, no Brasil, somente $8 \%$ da população (13,6 milhões de pessoas) acessam a internet a partir de computadores localizados em casa (pesquisa do Ibope e-Ratings.com). Esse autor afirma ainda que $80 \%$ desses internautas pertencem às classes A e B.

O governo brasileiro tem incentivado e investido em várias frentes e programas visando incentivar a inclusão digital. Mas, com relação às pessoas com necessidades especiais, Dias (2007) afirma que, no Brasil, há falta de dados estatísticos atualizados com relação a esse quantitativo. Por esse motivo, as entidades públicas e privadas adotam o percentual de $10 \%$, o que equivale a 17 milhões de brasileiros com necessidades especiais, segundo o Censo de 2000 (IBGE, 2001).

A deficiência visual é uma dessas necessidades especiais. Essa deficiência se refere à situação irreversível de diminuição de resposta visual em virtude de causas congênitas ou hereditárias e pode ser classificada como leve, moderada, severa e profunda (cegueira). No Brasil, segundo Dias (2007), devido à inexistência de dados confiáveis, é utilizada a estimativa de $1 \%$ da população. Isso corresponde a 1.693 .000 pessoas com deficiência visual, considerando-se a população aferida no Censo 2000 (IBGE, 2001).

Os deficientes visuais são os que mais têm dificuldades no acesso ao conteúdo de páginas web apresentados via computador. Existem tecnologias assistivas que possibilitam e facilitam esse acesso, entre elas: software leitores de telas, monitores brailles, tradutor de texto em voz, navegador web textual, ampliador de tela, entre outros.

Mas, para que todas essas ações sejam possíveis, é necessário ter acessibilidade. Acessibilidade, segundo Dias (2007), é a capacidade de um produto atender às necessidades e preferências das pessoas, sendo também compatível com tecnologias assistivas. Na percepção dessa autora, um software é considerado acessí- 
vel quando qualquer pessoa (deficiente ou não), ao utilizá-lo, executa as mesmas funções e atinge os mesmos resultados. A ausência de acessibilidade pode gerar algumas dificuldades para os deficientes visuais, entre elas: interagir com um dispositivo diferente do teclado, distinguir os links de um documento, navegar através de conceitos espaciais.

Além da acessibilidade, outro fator inclusivo seria o quantitativo de pessoas com deficiência visual que tem acesso ao computador em suas residências ou através de Lan houses, Tele-centros etc. Considerando os baixos percentuais populacionais com relação à inclusão digital citados anteriormente, um questionamento se faz necessário: essas tecnologias assistivas para deficientes visuais estão disponíveis nesses outros ambientes?

Diante do exposto, pode-se inferir que a inclusão digital dos deficientes visuais envolve aspectos como: tecnologias assistivas existentes ou a desenvolver, acessibilidade das páginas na internet e, também, o acesso ao computador (ou ambiente $W W W$ ) com a utilização dessas tecnologias assistivas. Nesse contexto, justifica-se a presente pesquisa que objetiva investigar alternativas para promover a maior inclusão digital das pessoas com deficiência visual.

Assim sendo, o objetivo geral desta pesquisa é identificar soluções que promovam a maior inclusão digital para pessoas com deficiência visual, considerando suas necessidades atuais e as iniciativas nacionais e internacionais existentes.

São objetivos específicos deste trabalho:

- identificar estudos existentes sobre a acessibilidade na internet para deficientes visuais;

- identificar iniciativas nacionais e internacionais (livres ou não) e os seus aspectos relevantes que visam lidar com este problema;

- investigar as atuais necessidades (levantamento de requisitos) e/ou prioridades dos deficientes visuais com relação à acessibilidade de TI; e

- esquematizar uma proposta que atenda a algumas das principais necessidades apontadas. 


\section{A pessoa com deficiência e a inclusão social}

Segundo Sassaki (2003), usar ou não termos técnicos corretamente não é uma mera questão semântica ou sem importância. A terminologia correta é especialmente importante quando são abordados assuntos tradicionalmente eivados de preconceitos, estigmas e estereótipos, como é o caso das diversas deficiências verificadas em boa parte da população mundial.

O termo correto que se deve utilizar para referenciar uma pessoa "portadora de deficiência" é "pessoa com deficiência", conforme também expresso em tópico anterior (SASSAKI, 2003). Amaral (1995) define deficiência como toda alteração do corpo ou aparência física de um órgão ou de uma função, qualquer que seja sua causa, caracterizando-se por perdas ou alterações que podem ser temporárias ou permanentes e que influenciem a existência ou ocorrência de uma anomalia, defeito ou perda de um membro, órgão, tecido ou outra estrutura do corpo, incluindo a função mental.

O conceito de deficiência inclui, necessariamente, a incapacidade relativa, parcial ou total para o desempenho da atividade dentro dos padrões considerados normais para qualquer ser humano. De fato, os portadores de deficiência podem realizar qualquer tipo de atividade desde que tenham condições e apoios adequados às suas características (PEREIRA, 2009).

O Decreto no 3.298/99 e o Decreto no 5.296/04 conceituam como deficiência visual:

- Cegueira - a visual é igual ou menor que 0,05 no melhor olho, com a melhor correção óptica.

- Baixa Visão - acuidade visual entre 0,3 e 0,05 no melhor olho, com a melhor correção óptica.

- Casos em que a somatória da medida do campo visual em ambos os olhos for igual ou menor que $60^{\circ}$.

- Ocorrência simultânea de quaisquer das condições anteriores (PEREIRA, 2009).

O Decreto n 5.296/04 foi o responsável pela inclusão das pessoas com baixa visão nesse item. Essas pessoas são identificadas pelo fato de, mesmo usando 
óculos comuns, lentes de contato ou implantes de lentes intraoculares, não conseguirem ter uma visão nítida, podendo ter sensibilidade ao contraste, percepção das cores e intolerância à luminosidade, conforme o tipo de patologia causadora da perda visual (PEREIRA, 2009).

Vital (2009) destaca os dados do Censo do IBGE de 2000 em relação à população com algum tipo de deficiência visual:

- Incapaz de enxergar: 159.824

- Grande dificuldade permanente de enxergar: 2.398 .472

- Alguma dificuldade permanente de enxergar: 14.015.641

- Total: 16.573 .937

\subsection{Inclusão social}

Pode-se considerar que as preocupações com a inclusão social iniciaram-se com o intenso movimento mundial de defesa dos direitos das minorias, na década de 1960, associado às críticas contundentes ao paradigma da institucionalização de pessoas com doença mental e de pessoas com deficiência. Esse movimento determinou novos rumos às relações da sociedade com esses segmentos populacionais. Desse modo, iniciaram-se os serviços de Reabilitação Profissional, voltados para as pessoas com deficiência, visando prepará-las para a integração ou reintegração na vida em comunidade (ARANHA, 2004, p. 25).

Nas décadas de 1970 e 1980, passou-se a buscar, para o tratamento e atendimento da deficiência, um novo modelo - o princípio da normalização - no qual se entendia que as pessoas com deficiência podiam ser normalizadas e capacitadas para viver em sociedade. Nesse modelo, busca-se capacitar as pessoas com deficiência a essa nova concepção-modelo (ainda segregadora), denominada de paradigma de serviços. A evolução desse paradigma, posteriormente, foi denominada paradigma de suportes ou paradigma inclusivo. Esse tipo de paradigma associou a ideia da diversidade como fator de enriquecimento social e o respeito às necessidades de todos os cidadãos como pilar central de uma nova prática social: "a construção de espaços inclusivos em todas as instâncias da vida social” (ARANHA, 2004, p. 25). 
A década de 1990 e início do século XXI significaram o avanço dos estudos sobre a presença das pessoas com algum tipo de deficiência no âmbito social em todo o Brasil, por meio da intensificação de cursos de pós-graduação e de ações específicas do Governo Federal em relação ao referido público (ARANHA, 2004).

A influência da educação na inclusão social das pessoas que possuem algum tipo de deficiência é primordial. Tanto que, em 2003, o Ministério da Educação (MEC), por meio da Secretaria de Educação Especial (SEE), assume o compromisso de apoiar os Estados e Municípios na tarefa de fazer com que as escolas brasileiras se tornem inclusivas, democráticas e com ensino de qualidade. Com isso, desde 2003, a política educacional brasileira vem criando instrumentos legais para garantir o acesso imediato de pessoas com necessidades educacionais especiais, de modo a favorecer a participação de todos os grupos sociais, independentemente das suas necessidades educacionais especiais, do tipo de deficiência e/ou do grau de comprometimento que essas apresentam.

A inclusão social de pessoas com deficiência é resultado de inúmeros estudos e discussões que contaram com a participação de organizações, educadores, pessoas com necessidades especiais e seus familiares, não só aqui no Brasil, mas em todo o mundo. Segundo o Programa Educação Inclusiva: Direito à Diversidade (2004, p. 14), ${ }^{4}$ "a Assembleia Geral da Organização das Nações Unidas (ONU) produziu vários documentos norteadores para o desenvolvimento de políticas públicas de seus países membros".

\section{Acessibilidade e ferramentas de acessibilidade na TI}

A difusão do conceito de acessibilidade iniciou-se em 1981, ano declarado pela Organização das Nações Unidas (ONU) como "Ano Internacional dos Portadores de Deficiência”. Já no Brasil, o direito de as pessoas com deficiência

4 O Ministério da Educação (MEC), por meio da Secretaria de Educação Especial (SEE), implementa o Programa Educação Inclusiva: Direito à Diversidade, que tem por objetivo compartilhar novos conceitos, informações e metodologias - no âmbito da gestão e também da relação pedagógica em todos os estados brasileiros. 
terem as mesmas oportunidades que os demais cidadãos possuem e de desfrutarem as condições de vida resultantes do desenvolvimento econômico e social foi proporcionado pela Constituição Federal (CF) de 1988, a qual prevê o pleno desenvolvimento dos cidadãos, sem preconceito de origem, raça, sexo, cor, idade e quaisquer outras formas de discriminação; garante o direito à escola para todos; e coloca como princípio para a Educação o "acesso aos níveis mais elevados do ensino, da pesquisa e da criação artística, segundo a capacidade de cada um" (BRASIL, 1999).

De acordo com a Associação Brasileira de Normas Técnicas - ABNT (2004), acessibilidade é ter acesso a todo e qualquer espaço, seja físico ou de comunicação, proporcionando assim a entrada aos diferentes tipos de pessoas com necessidades educacionais especiais (crianças, idosos, gestantes etc.) aos locais por elas frequentados, garantindo-lhes qualidade de vida, por meio da Lei $n^{\circ}$. 10.098/2000, que estabelece normas gerais e critérios básicos para a promoção da acessibilidade das pessoas portadoras de deficiência ou com mobilidade reduzida.

No escopo da acessibilidade, temos ainda a acessibilidade digital, considerando que a atual geração está sendo caracterizada como a geração digital ou os filhos da era digital. Entretanto, ao que se pode observar no relatório produzido pelo IBGE, fruto da Pesquisa Nacional por Amostra de Domicílios - PNAD de 2005, há um baixo nível de acesso à internet nas escolas (12\%), sendo que, nos países avançados, acima de $80 \%$ dos alunos jovens na mesma situação têm essa possibilidade. Também surpreende a baixa disponibilidade de centros de acesso gratuito, permitindo acesso à internet só a 4,4\% dos jovens. É importante ressaltar que essas informações correspondem a alunos videntes e com deficiência visual. Pode-se inferir que os problemas de acessibilidade digital são maiores quando o foco são as pessoas com deficiência visual.

No caso da deficiência visual, a acessibilidade digital é garantida por uma série de padrões. O W3C (World Wide Web Consortium) é o órgão que coordena a elaboração e padronização das regras de acessibilidade. Essas regras são adotadas por diversos países e empresas como a IBM e Microsoft.[1,2]. As orientações elaboradas pelo W3C têm como objetivo auxiliar e encorajar o desenvolvimento 
de páginas acessíveis, indicando não só princípios gerais como as formas ideais de implementação que orientam os autores (RODRIGUES et al.,[2009]).

O W3C publicou, em 5 de maio de 1999, o primeiro documento: "Web Content Accessibility Guidelines" . Esse documento foi elaborado com o objetivo de propor sugestões de como tornar o conteúdo de documentos web acessível a portadores de deficiência (Web Content Acessibility Guidelines 1.0). Além desse documento, temos ainda técnicas de cores para utilização de contraste para deficientes visuais com problemas de baixa visão e daltonismo, definidas no WCAG 2.0 (Web Content Accessibility Guidelines).

No que tange aos deficientes visuais, é fácil perceber que construir uma interface é algo complexo, que deve seguir algumas regras de lógica, funcionalidade e ergonomia muito particulares, e que serão parte fundamental no sucesso de um produto. É importante notar que não é suficiente uma adaptação, uma interface já padronizada, bastante conhecida e consolidada, pois isso não garante que ela seja acessível às pessoas cegas (PINHEIRO, 2004). Por exemplo, o uso do mouse pelo deficiente visual torna-se quase impossível, visto que sua operação é predominantemente visual. Existem programas que só conseguem disparar certas funções a partir de um clique do mouse, prejudicando o seu uso por deficientes visuais.

Apesar dessas dificuldades, com a ajuda de computadores, scanners, impressoras e outros equipamentos, um cego é capaz de "escrever e ser lido, e ler o que os outros escreveram". A vertente brasileira dessa tecnologia é o projeto DOSVOX (BORGES, 1996 apud BORGES; JENSEN, [2002]), sistema de computação baseado em síntese de fala que permitiu o acesso ao computador a mais de 3000 pessoas cegas no Brasil, eliminando muitas sérias restrições para a comunicação com pessoas não cegas, e que foi base de construção para o presente Projeto.

O Jaws também é outra opção de leitor de telas. É um programa desenvolvido pela empresa norte-americana Henter-Joyce, pertencente ao grupo Freedom Scientific. O Jaws permite ao usuário trabalhar com diferentes versões do sistema operacional Windows e com seus aplicativos, é utilizado também para acessar conteúdo web (se o site for estruturado corretamente e bem organizado) (INSTITU- 
TO FEDERAL DE EDUCAÇÃO, CIÊNCIA E TECNOLOGIA (IFET), 2009) Com o Jaws, qualquer usuário deficiente visual pode trabalhar tão ou mais rapidamente do que uma pessoa que veja normalmente, utilizando teclas de atalho. Estima-se que, atualmente, a quantidade de usuários desse programa esteja em torno de 50.000, espalhados por vários países (CHIAPETTI, 2007).

A seguir seguem alguns exemplos de teclas de atalho para o funcionamento do Jaws (IFET, 2009)

- Tecla Iniciar + M: Vai direto para a Área de Trabalho.

- Insert + T: diz o Título da Janela que está sendo utilizada.

- CTRL ESC ou tecla com o desenho da janelinha (botão iniciar): ativa Menu Iniciar

- TAB: avança controle (alterna entre as partes de uma janela e as partes do Windows)

- SHIFT TAB: recua controle (alterna entre as partes de uma janela)

- SETAS: alternam em uma parte específica da janela.

- CTRL TAB: vai p/a próxima guia de uma janela.

- CTRL SHIFT TAB: vai para a guia anterior de uma janela.

- ALT TAB: alterna entre as janelas ativas que estão na barra de tarefas (próxima)

- ALT SHIFT TAB: alterna entre as janelas ativas que estão na barra de tarefas (anterior)

- ALT ESC: memoriza uma janela / vai para uma janela não aberta

- INICIAR M: vai para a área de trabalho

- ESPAÇO: executa o controle selecionado

- ENTER: ativa atalho (ícone) ou botão ativo (selecionado)

- ALT $\downarrow \downarrow \downarrow$ : abre caixa combinada selecionando um item da mesma

- ALT ESPAÇO: ativa menu controle de uma janela

- ENTER: Ativa o modo formulário (para preencher algo)

- ESPAÇO + ENTER: Marca botão de rádio

Quanto ao preço, a versão demo de 40 minutos pode ser capturada do site do fabricante gratuitamente; a versão demo de 60 dias está disponível por baixo preço; a versão para Windows 95/98 e a versão completa para Windows NT ou 2000 
são mais onerosas. As licenças para empresa estão disponíveis em múltiplos de cinco, com descontos variando de 30 a 40\%, dependendo do número de usuários.

O Virtual Vision é um leitor de tela desenvolvido pela MicroPower (empresa de Ribeirão Preto - SP). Pode ser adaptado em qualquer programa do Windows. É uma aplicação da tecnologia de síntese de voz, um "leitor de telas" capaz de informar aos usuários quais os controles (botão, lista, menu etc) que estão ativos em determinado momento. Pode ser utilizado inclusive para navegar na internet. Segundo informações de seu fabricante, o Virtual Vision é atualmente acessado por aproximadamente 4.500 pessoas (CHIAPETTI, 2007).

No que tange ao preço do Virtual Vision, a versão atual é comercializada, sendo gratuita para correntistas do Bradesco. As versões para Windows XP, NT e 2000 são mais caras. Programas similares importados têm preços superiores (CHIAPETTI, 2007).

Há também o Lente-Prom, um programa do Projeto Dosvox, pelo Núcleo de Computação Eletrônica da Universidade Federal do Rio de Janeiro (NCE-UFRJ), que permite o uso do computador por pessoas que possuem visão subnormal. Por meio dele, o que aparece na tela é ampliado em uma janela (como se fosse uma lupa). O índice de ampliação da imagem dessa janela pode variar de 1 a 9 vezes, permitindo assim que todos os detalhes sejam percebidos mesmo por aqueles com grau muito baixo de acuidade visual. O programa é simples de ser utilizado, ocupa pouco espaço de memória, além de permitir várias alternativas de configuração.

Ainda é possível testar a acessibilidade em diversos browsers, incluindo os browsers com capacidade de sintetizar voz com leitores de tela e validar com ferramentas de validação como as citadas a seguir:

- BOBBY: http://www.cast.bobby.org

- W3C HTML Validation Service: http://validator.w3c.org

- DaSilva: http://www.dasilva.org.br/

- Web@x Examinator: http://www.acesso.umic.pt/webax/examinator.php

- Hera: http://www.sidar.org/hera/index.php.pt 
Além dos validadores de padrões W3C citados anteriormente, existem ferramentas de validação de padrões de cores e contrastes para os deficientes visuais como as citadas a seguir:

- Snoock.ca: http://www.snook.ca/technical/colour_contrast/colour.html

- Juicy Studio: http://juicystudio.com/services/colourcontrast. php

Conforme pode ser observado, existem muitas ferramentas e padrões que permitem as pessoas com deficiência visual terem maior acessibilidade. Mas para que isso aconteça, é necessário que os desenvolvedores de páginas para web contribuam gerando páginas acessíveis e que existam cada vez mais ferramentas gratuitas e de boa qualidade de leitura dessas informações. Somente dessa forma se abrirá a possibilidade de acesso à informação para a comunidade de pessoas com deficiência visual.

\section{Metodologia}

Esta investigação utilizou a abordagem qualitativa. O estudo foi baseado no levantamento bibliográfico das abordagens existentes e nas percepções dos deficientes visuais e das pessoas que trabalham com os deficientes. A utilização de variados métodos (mixed methods research), segundo Creswell e Clark (2007), envolve coletar e analisar dados qualitativos e quantitativos, para melhor compreensão do problema da pesquisa. A utilização de métodos combinados ajuda a entender questões que podem não ser respondidas somente pela abordagem qualitativa ou quantitativa, possibilitando a utilização de múltiplas visões de mundo ou paradigmas.

A forma mais comum de misturar métodos é o desenho de triangulação. Existem várias propostas de triangulação; nesta pesquisa, busca-se obter informações diferentes, mas complementares, dadas sobre o mesmo tópico para melhor entender o problema da pesquisa.

No que tange ao alcance temporal, a pesquisa se caracteriza como uma pesquisa interseccional, uma vez que investiga as necessidades do deficiente visual em determinado período. O método adotado foi o Estudo de Caso, e os instrumentos 
de coleta de dados aplicados foram a pesquisa bibliográfica e as entrevistas semiestruturadas. É interessante ressaltar que o Estudo de Caso é uma investigação empírica que pesquisa fenômenos dentro do seu contexto real, no qual o pesquisador não tem controle sobre eventos e variáveis, buscando descrever, compreender e interpretar a complexidade de um caso concreto (KOLHBACHER, 2006).

Algumas características são essenciais para garantir a eficácia e a credibilidade da estratégia Estudo de Caso, segundo Yin (2001):

- Validade do constructo - obtida por meio de constructos validados por revisão de literatura, utilização de múltiplas fontes, estabelecimento de caminhos de evidência. Neste estudo, fez-se uma ampla revisão de literatura com utilização de múltiplas fontes.

- Validade interna ou credibilidade - é estabelecida utilizando análises e análises cruzadas, assegurando a coerência interna dos achados e utilizando a triangulação como técnica para aumento da credibilidade. Essa triangulação foi possível por meio da revisão bibliográfica e da coleta das percepções dos videntes e deficientes visuais.

- Validade externa - garante que o escopo da pesquisa realizada pode ser replicado em casos de estudos aproximados. Envolve descrições sobre caso de estudo, protocolo de intenções de entrevistas e procedimentos para codificação e análise. Os protocolos de pesquisa e instrumentos de coleta estão relacionados na pesquisa.

- Confiabilidade - habilidade para que outros pesquisadores possam aplicar este Estudo de Caso e encontrar resultados similares. A confiabilidade foi garantida por meio de registro dos dados coletados para que outros pesquisadores possam seguir o caminho da evidência e replicar em outros contextos.

Para a análise dos dados coletados das entrevistas, foi utilizada a técnica de análise de conteúdo. As entrevistas foram gravadas e posteriormente transcritas. Considerando o público da pesquisa, o TCLE foi lido anteriormente à aplicação da entrevista e foi obtido o consentimento nesse momento. A elaboração das questões da entrevista ocorreu após a pesquisa bibliográfica, pois os dados desta pesquisa serviram como subsídio. 
De acordo com a Organização Mundial da Saúde (OMS), em torno de 0,5\% da população possui deficiência visual grave (baixa visão ou cegueira). Segundo o IBGE, com base no Censo de 2000, o número de pessoas com deficiência visual (incapazes ou com pequena ou grande dificuldade permanente) é de 16.573.937 (aproximadamente 10\%). Os indivíduos que têm grande dificuldade permanente de enxergar correspondem a 2.398.472 (1,4\%), e os incapazes de enxergar somam 159.824 (aproximadamente 1\% da população). A população do Distrito Federal, segundo o IBGE (2000), é de 2.051.146 habitantes. Adotou-se, então, para a pesquisa, a noção de deficiente visual como a pessoa com baixa visão ou cegueira permanente. Com base nisso, estima-se que o quantitativo de deficientes visuais esteja entre $1 \%$ e 1,5\% da população do DF. Ou seja, aproximadamente entre 20.511 e 30.767 indivíduos.

Identificou-se a Associação Brasiliense de deficientes visuais - ABDV, como uma entidade de classe localizada em Brasília, que agrega mais de 800 associados portadores de deficiência visual. Identificou-se também o CEEDV - Centro de Ensino Especial para Deficientes Visuais, como outra entidade localizada em Brasília, que atende aos portadores de deficiência visual. O CEEDV tem atualmente 215 alunos.

O critério para seleção dos participantes deficientes visuais foi definido, principalmente, com relação à utilização dos recursos tecnológicos (focando principalmente o Computador e a Internet) e com relação à idade (maior que 18 anos). Na ABDV, utilizou-se também outro critério de participação. Apesar do grande número de associados, somente 50 deficientes visuais têm participação ativa junto a essa entidade. Assim sendo, definiu-se a população considerando os critérios citados anteriormente e esses 50 deficientes. Identificou-se que a maior parte desses deficientes atendia aos dois critérios (maior de 18 anos e utilizava tecnologia), assim sendo, definiu-se a população em 50 indivíduos.

No CEEDV, utilizou-se, além dos critérios de idade e conhecimento tecnológico, o critério de participação/utilização dos recursos computacionais no ambiente, ou seja, definiu-se a população de deficientes visuais da pesquisa, considerando os critérios citados anteriormente, e se participavam de algum curso ou 
treinamento envolvendo recursos computacionais. Isso resultou em uma população de 28 participantes.

Com relação à população de videntes participantes da pesquisa, foram considerados todos os professores que ministram algum tipo de treinamento no CEEDV, utilizando recursos computacionais. Foram identificados 4 professores.

A pesquisa qualitativa foi realizada sobre uma pequena amostra da população definida, considerando os critérios estabelecidos. Não foram identificadas outras entidades de classe ou mesmo ONGs em Brasília que agregam pessoas com deficiência visual (foco da pesquisa).

A pesquisa para os deficientes visuais consistiu em um total de 19 perguntas direcionadas aos participantes do levantamento, sendo que as respostas e artefatos finais foram gerados em formato de arquivos de áudio (MP4), gravados em mídia apropriada (CD-R), tendo em vista a impossibilidade de os participantes responderem às questões de forma escrita. Para os videntes, a pesquisa teve 17 questões. Os termos de ciência de participação dos participantes da pesquisa foram lidos e esclarecidos junto a eles, sendo também a autorização para tal pesquisa também gravada.

\section{Aplicação do instrumento de coleta e resultados obtidos}

Foram entrevistadas 26 pessoas deficientes visuais, das duas entidades, entre os dias 12/02/2010 e 26/08/2010, sendo que todas apresentam deficiência visual, dentre as quais, quinze $(55,5 \%)$ apresentam cegueira total e doze $(44,5 \%)$ apresentam baixa visão. Como os entrevistados possuem problemas visuais, as entrevistas foram gravadas em DVD no formato WAV, seguindo o padrão de nomenclatura DDMMAAAA_no da entrevista_LOCAL DA ENTREVISTA.WAV. Dentre os entrevistados, cinco deles são ligados à ABDV (Associação Brasiliense de Deficientes Visuais) e vinte e duas pessoas são ligadas à CEEDV (Centro de Ensino Especial para Deficientes Visuais). Foram entrevistados 4 professores videntes que trabalham com os deficientes visuais utilizando recursos tecnológicos, visando à triangulação dos resultados. 
Identificou-se que a faixa etária predominante dos entrevistados deficientes visuais está compreendida entre 21 e 40 anos de idade, conforme a Figura 1. A faixa etária dos professores que trabalham com os deficientes visuais está compreendida entre 21 e 40 anos (2 participantes) e 41 a 60 anos (2 participantes).

Desse quantitativo de deficientes visuais, quinze são do sexo masculino (59\%) e onze do sexo feminino (41\%), possuindo grau de instrução diversificado, mas, em sua maioria, são indivíduos com Ensino Médio completo e que possuem, como principal ocupação, os estudos (Figura 2). Com relação aos professores videntes, o grau de escolaridade ficou entre Superior completo (3 participantes) e pós-graduação (1 participante).

No universo da pesquisa, foi verificado que todos os deficientes visuais têm contato com tecnologia por meio de computadores ou celulares, seja em seu domicílio, em escolas ou ainda no local de trabalho, porém nem todos possuem condições de ter contato com as ferramentas de acessibilidade em computadores, tendo em vista a condição econômica da maioria dos entrevistados. O principal local de contato dos entrevistados com computadores e as ferramentas de acessibilidade se restringem muitas vezes ao local de estudo ou trabalho, conforme Figuras 3, 4 e 5. O tempo de uso diário do computador está demonstrado na figura 5.

Figura 1 - Participantes deficientes visuais por faixa etária

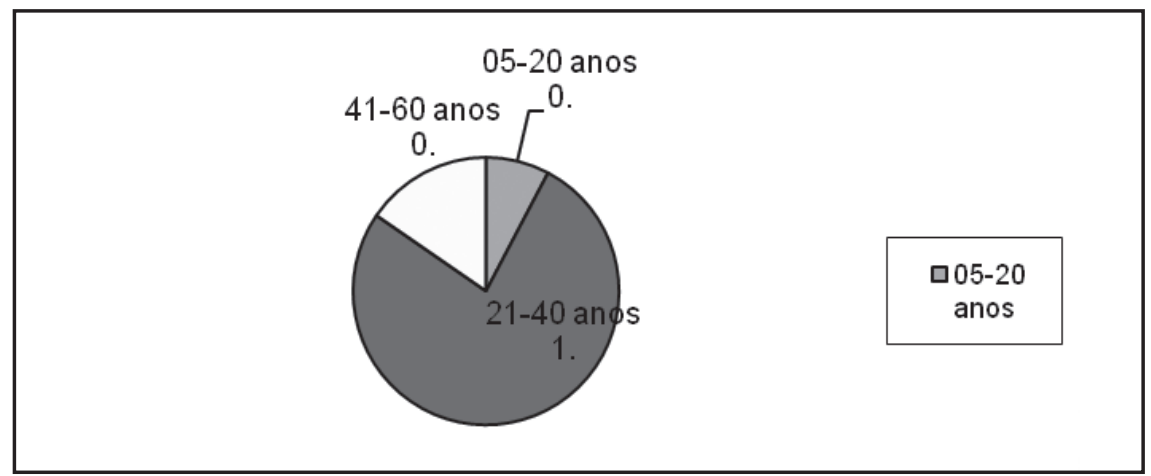

Fonte: do autor 
Figura 2 - Participantes deficientes visuais por sexo

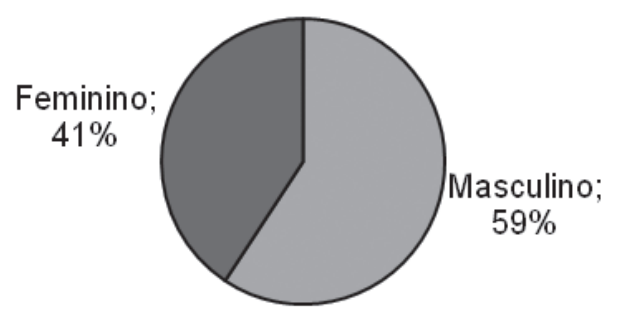

Fonte: do autor

Figura 3 - Perfil dos respondentes deficientes visuais

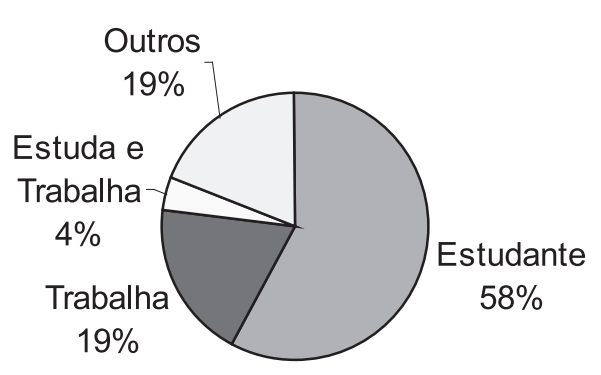

$\square$ Estudante

$\square$ Trabalha

$\square$ Estuda e Trabalha

$\square$ Outros

Fonte: do autor

Figura 4 - Utilizam celular - deficientes visuais

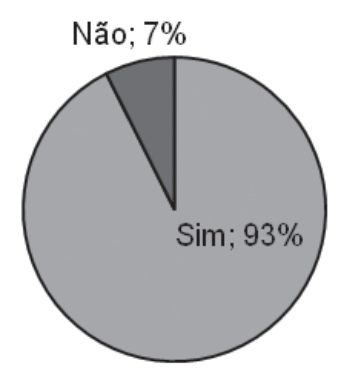


Figura 5 - Tempo de utilização do computador - deficientes visuais

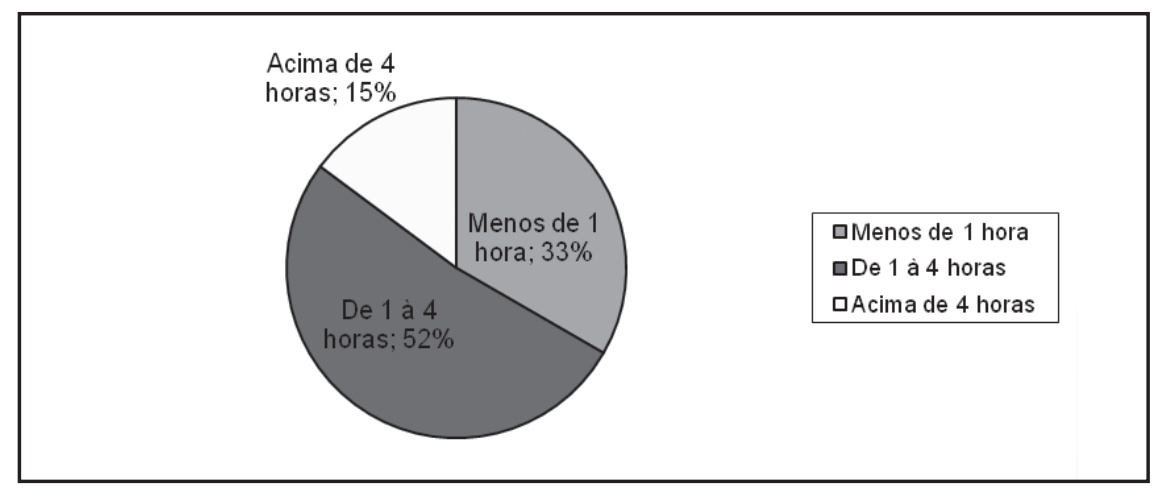

Fonte: do autor

Isso justifica o grau de conhecimento dos entrevistados com relação às ferramentas de acessibilidade, nas quais 51\% dos entrevistados estão compreendidos entre os níveis regular e insuficiente, já que o contato dos usuários com as ferramentas está diretamente ligado ao grau de domínio sobre essas ferramentas. Já $100 \%$ dos videntes consultados declararam ter bom conhecimento com relação às ferramentas de acessibilidade. É interessante ressaltar que todos os videntes trabalham com deficientes visuais de 0 a 5 anos.

Outro fator que aponta para o baixo grau de domínio das ferramentas pelos deficientes visuais é o alto preço delas, tendo em vista que os valores das licenças de software são elevados e a maioria não possui condição de realizar a compra (Figura 6). Entre os usuários de celular (93\%), o índice de pessoas que não utilizam ferramentas de acessibilidade chega a 45,5\%, pois além da própria ferramenta, é necessário um aparelho de celular que comporte a sua instalação. Nessa questão, os videntes consultados concordam que o preço é um dos fatores que impactam e geram o baixo grau de domínio das ferramentas pelos deficientes visuais. Mas também assinalam a falta de equipamento e a difícil usabilidade dos produtos. 
Figura 6 - Maior inconveniente das ferramentas na percepção dos deficientes visuais
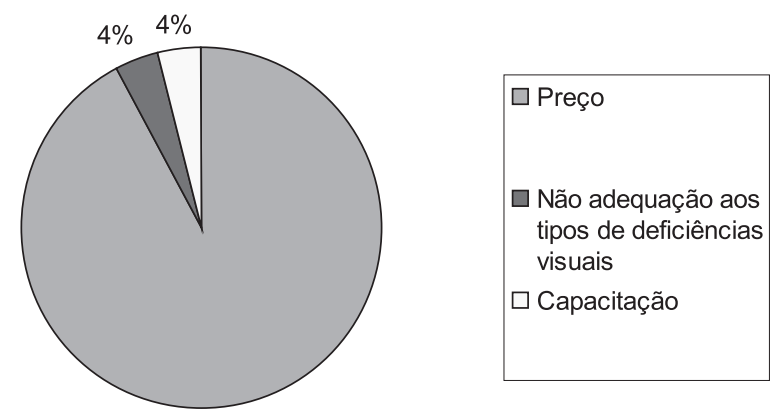

$92 \%$

Fonte: do autor

Além do preço, outros fatores como a não adequação das ferramentas aos vários tipos de softwares existentes e a própria capacitação dos usuários para utilização do software foram também citados pelos deficientes visuais.

Apesar das facilidades que as ferramentas proporcionam aos usuários deficientes visuais, ainda existem fatores que atrapalham os deficientes visuais, como a não padronização na construção de páginas da web no padrão W3C, em especial ao padrão WCAG 2.0, regulamentação que, se seguida à risca, possibilitaria a leitura de tais páginas de maneira muito mais eficiente. Os entrevistados também citaram que nem sempre as ferramentas conseguem ler os programas, gráficos ou páginas, e essa navegação se torna cansativa e não possui um padrão, ou seja, cada página construída possui uma disposição de itens diferentes; e o aprendizado, quando à navegação nas páginas, também é um fator para o sucesso de utilização dos softwares de acessibilidade. Três videntes pesquisados (75\%) identificaram DosVox, Jaws e Virtual como principais ferramentas que facilitam a acessibilidade e que são utilizadas pelos deficientes no seu ambiente de estudo (CEEDV).

Os entrevistados deficientes visuais sugeriram também que a melhoria nas ferramentas atuais facilitaria a sua acessibilidade. Essa sugestão foi ratificada pelas respostas dos videntes. Com relação a ferramentas de acessibilidade para celular, foi detectado que a maioria dos participantes $(80 \%)$ que tem telefone celular utiliza 
a ferramenta Talks, e que o grau de conhecimento dessa ferramenta está classificado entre ótimo e bom.

Os entrevistados deficientes visuais evidenciaram que o trânsito, o estudo e o trabalho são as situações que necessitam de mais ferramentas para auxiliá-los. Podemos citar, por exemplo, a necessidade de ferramentas e meios para um deficiente visual realizar as compras em um supermercado e possibilitar a identificação dos produtos, guiando-o para os setores/áreas de produtos (Figura 11). Os videntes entrevistados (75\%) também identificaram o estudo e o trabalho como as situações em que os deficientes mais necessitam de ferramentas de acessibilidade.

Dentre outras necessidades apontadas pelos entrevistados deficientes visuais em que a informática poderia ser utilizada para suprir outras necessidades, a locomoção, o transporte e a acessibilidade, de um modo geral (leitor de telas, scanner de textos com OCR, caixa eletrônicos, teclado em Braille etc.), estão entre aquelas que poderiam ser supridas. Essa questão também foi evidenciada nas respostas dos videntes, nas quais $75 \%$ citaram a melhoria da acessibilidade de uma forma geral. Isso evidencia que as ferramentas atuais não atendem totalmente às necessidades dos entrevistados.

Figura 7 - Situações/atividades ou áreas em que o deficiente visual necessita de mais ferramentas para auxiliá-lo na percepção dos objetos

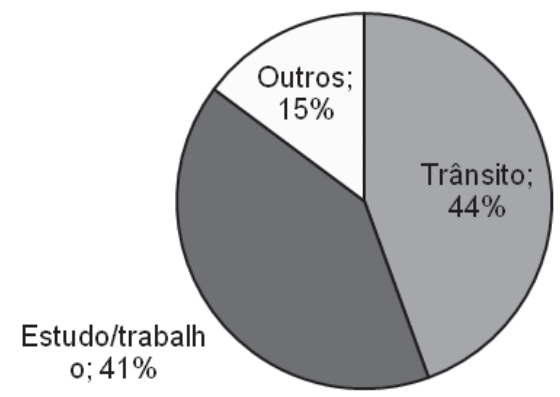

םTrânsito

口Estudo/trabalho

口Outros

Fonte: do autor 
Também foi possível identificar ideias de ferramentas a serem projetadas para os deficientes, de acordo com a visão dos entrevistados, sendo que o universo de respostas foi diversificado, mas ainda assim compreendido em um universo de soluções para a locomoção em locais públicos e no auxílio ao transporte dos deficientes visuais, conforme listagem a seguir:

- bengala sensível ao toque;

- bengala com sensores de objetos;

- GPS adaptado para deficientes visuais em conjunto com o software;

- talks;

- alarme sonoro nas paradas de ônibus, aviso sonoro para identificar os ônibus ou o transporte público (sistema de áudio);

- programas de lazer mais interessantes para os deficientes;

- um programa de ilustração (tipo Corel Draw) para deficientes visuais;

- locomoção em carros para deficientes visuais;

- sinal sonoro nas pistas/ruas que avise quando tem bancos, mercados etc.;

- texturas de pisos diferentes para reconhecer os estabelecimentos;

- facilidade de acesso à empresa, diminuindo o custo de adaptação do local de trabalho;

- luz noturna para quem usa bengala e em placas para deficiente de baixa visão;

- ferramenta que cria um diário de classe eletrônico que pudesse ser lido pelos leitores de tela, facilitando o acesso aos conteúdos escolares;

- fone de ouvido com leitor de texto direcionável, dispensando o livro em formato Braille; e

- software sonoro para elevadores, indicando o andar, o sentido, o fechamento e abertura das portas automáticas.

\section{Conclusão}

O objetivo geral desta pesquisa foi identificar as soluções que promovem a maior inclusão digital para pessoas com deficiência visual, considerando suas ne- 
cessidades atuais e as iniciativas nacionais e internacionais existentes e, para atender a esse objetivo, investigaram-se, inicialmente, os conceitos sobre o portador de deficiência, inclusão social e acessibilidade.

Foram realizados estudos existentes sobre a acessibilidade na internet para deficientes visuais, identificando as iniciativas nacionais e internacionais (livres ou não) e os seus aspectos relevantes, que visam lidar com esse problema. Assim sendo, a aplicação do instrumento de coleta permitiu investigar as atuais necessidades (levantamento de requisitos) e/ou prioridades dos deficientes visuais com relação à acessibilidade de TI e também em outros contextos. Além disso, buscou-se a triangulação desses resultados por meio da percepção dos professores de deficientes visuais que utilizam recursos tecnológicos.

Após esta pesquisa, foi possível concluir que a acessibilidade para deficientes visuais como um fator de inclusão social, segundo os participantes da pesquisa, ainda necessita de muitas ações de melhoria para ser considerada adequada. Como as necessidades dos videntes não são as necessidades dos deficientes visuais, isso gera, na maior parte das vezes, uma lacuna de compreensão a ser preenchida para se alcançar a inclusão social por meio da tecnologia.

Por serem uma minoria dentro da sociedade, ainda são muitas as necessidades dos deficientes visuais. Essas necessidades decorrem, muitas vezes, da falta de aplicação das leis que garantem aos deficientes os mesmos direitos dos videntes. Essas leis existem e foram citadas neste trabalho, mas, infelizmente, não são cumpridas em sua integralidade.

A pesquisa identificou que o preço é o maior inconveniente das ferramentas de acessibilidade. Outros fatores, como a não adequação das ferramentas aos vários tipos de deficiência visual e a própria capacitação dos usuários para utilização do software, também foram citados. Com relação a esse tópico, é importante ressaltar que existem várias iniciativas de software livre despontando no mercado. É também uma visão geral dos entrevistados que essas ferramentas de acessibilidade devem ser livres, permitindo, dessa maneira, a possibilidade de imersão na tecnologia aos mais necessitados, e que 
precisam de incentivo, tanto governamental como de entidades parceiras sem fins lucrativos.

Com os resultados da pesquisa e considerando todas as necessidades apontadas, esquematizar uma única proposta para atender a algumas das principais necessidades apontadas (último objetivo específico) foi inviável. Assim sendo, sugere-se, inicialmente, uma ação de capacitação dos deficientes visuais nas ferramentas existentes. Essa capacitação seria essencial para a identificação mais pontual dos pontos a serem melhorados nessas ferramentas (leitura de gráficos etc). Sugere-se também que o Projeto de Inclusão Digital do UniCEUB patrocine essa ideia de forma a disseminar a inclusão digital, inclusive para essa camada da população tão carente de recursos.

Como sugestões para futuras pesquisas, indicam-se algumas das sugestões apontadas nas entrevistas, tais como: bengala sensível ao toque, bengala com sensores de objetos, GPS adaptado para deficientes visuais em conjunto com o software Talks, ferramenta que cria um diário de classe eletrônico que possa ser lido pelos leitores de tela, facilitando o acesso aos conteúdos escolares, fone de ouvido com leitor de texto direcionável, dispensando o livro em formato Braille.

Os entrevistados também apontaram como grande problema a falta de tecnologias aplicadas ao trânsito, ficando assim como mais uma sugestão para pesquisas futuras.

\section{Accessibility for people with visual impairments as a factor for digital inclusion}

\section{Abstract}

The research's objective was identify solutions that promote greater digital inclusion for people with visual impairments, considering your current needs and the national and international existence of iniciatives. Qualitative research, conducted through interviews with visually impaired people and sighted people working with the visually impaired, has enabled the triangulation of results. The 
study found that possible initiatives to increase accessibility for the visually impaired people to digital media are fundamentally supported by W3C framework and iniciatives led by universities in search for new solutions. The research showed that despite the existing iniciatives, the digital inclusion of visually impaired people is far from ideal and the lack of initiatives to increase the effective use of technology to those users is a reality and is a reflection of the society built on individuals without disabilities.

Keywords: Digital inclusion. Visual impairment. Digital illiteracy. Accessibility. Accessibility tools. Social inclusion. People with disabilities

\section{Referências}

ASSOCIAÇÃO BRASILEIRA DE NORMAS TÉCNICAS. NBR 9050: acessibilidade e edificações, mobiliário, espaços e equipamentos urbanos. 2 ed. Rio de Janeiro: ABNT, 2004.

AMARAL, Roberto. Ciência e tecnologia: desenvolvimento e inclusão social. Brasília: UNESCO, Ministério da Ciência e Tecnologia, 2003.

ARANHA, M. S. F. Educação inclusiva: transformação social ou retórica? In: Omote, S. (org.) Inclusão: Intenção e Realidade. Conferência proferida durante a VII Jornada de Educação Especial, UNESP-Campus de Marília. São Paulo: Fundepe, 2004.

AZEVEDO, Alexandre Costa Lima. Legislação relacionada à deficiência visual. Disponível em: <http:/www.institutodavisao.org.br/conteúdos tmpArquivos/ legislacao_deficiencia_visual.pdf/>. Acesso em: 15 fev. 2009.

BRASIL. Lei n. 7.853, de 24 de outubro de 1989. Dispõe sobre o apoio as pessoas portadoras de deficiência, sua integração social, sobre a Coordenadoria Nacional para Integração de Pessoa Portadora de Deficiência (Corde), institui a tutela jurisdicional de interesses coletivos ou difusos dessas pessoas, disciplina a atuação do Ministério Publico, define crimes e dá outras providências. Disponível em: < http://www.planalto.gov.br/ ccivil_03/leis/L7853.htm>. Acesso em: 18 mar. 2010.

BRASIL. Decreto Lei $n$. 3298, de 20 de dezembro de 1999. Regulamenta a Lei 7.853, de 24 de outubro de 1989, dispõe sobre a Política Nacional para a Integração da Pessoa Portadora de Deficiência, consolida as normas de proteção e dá outras providências. 
Disponível em: < http://www.planalto.gov.br/ccivil_03/decreto/d3298.htm >. Acesso em: Acesso em: 25 mar. 2010.

BRASIL. Ministério de Planejamento, Orçamento e Gestão. Secretaria de Logística e Tecnologia da Informação. Departamento de Governo Eletrônico. Recomendações de acessibilidade para a construção e adaptação de conteúdos do governo brasileiro na Internet: eMag, acessibilidade de governo eletrônico modelo de acessibilidade. Versão 2.0. Brasília, 2005. Disponível em: <http://www. inclusaodigital/gov.br/inclusao/arquivos/ outros/documentos-gerais-referencias/ emag-acessibilidade-de-governo-eletronico-modelo-v20.pdf $>$. Acesso em: 20 abr. 2008.

BORGES, José Antônio; JENSEN, Leo Roberto. Cegos e Computador: Uma Interação que Explora o Potencial do Desenho. Projetos de Acessibilidade do NCE/UFRJ, Rio de Janeiro, [2002]. Disponível em: < http://intervox.nce.ufrj.br/dosvox/textos/ semenge.doc>. Acesso em: 10 mar. 2010.

CAMARGO, Paulo. O primeiro ano de vida da criança e a intervenção sobre seu desenvolvimento neuropsicomotor. IN.: KUDO, Aide M. (et al.). Fisioterapia, Fonoaudiologia e Terapia Ocupacional em Pediatria. $2^{\circ}$ ed. São Paulo: Sarvier, 1994.

CARVALHO, M. P. Trabalho docente e relações de gênero: algumas indagações. Revista Brasileira de Educação. São Paulo, n. 2, mai/jun/jul 1996, p.77-8

CHIAPETTI, Rosevani. Inclusão digital a invisuais. Pato Branco: FADEP, 2007. Trabalho de Conclusão de Curso (Bacharelado) - Curso de Psicologia, Faculdade de Pato Branco, Pato Branco, PR, 2007.

CRESWELL, John W.; CLARK, Vicki L. Designing and conducting mixed methods research. California: Sage Publications, 2007.

DIAS, Claudia. Usabilidade na WEB. Rio de Janeiro: Alta Books, 2007.

IBGE. Censo Demográfico 2000. Rio de Janeiro: Instituto Brasileiro de Geografia e Estatística, 2001.

INSTITUTO FEDERAL DE EDUCAÇÃO, CIÊNCIA E TECNOLOGIA (IFET). Manual Jaws. Núcleo de Atendimento às Pessoas com Necessidades Especiais, Sistema de Informações da Educação Profissional e Tecnológica. Rio Grande do Sul, Jan. 2009. Disponível em: <http://bento.ifrs.edu.br/acessibilidade/pdf/jaws.pdf >. Acesso em: 11 ago. 2011. 
KOLHBACHER, Florian. The use of qualitative content analysis in the case study research. Forum: Qualitative Social Research, Berlin, v. 7, n. 1, art. 21, jan. 2006.

KOSE, S. (2004). Japanese Experience toward Accessible and Usable Built Environment: Lessons for the Developing Economies, Designing for the 21 st century III, Conference proceedings, Rio de Janeiro: 2004.Cdrom.

PEREIRA, Gorete. Tipos de deficiências. Gorete Pereira. Disponível em: <http:// www.goretepereira.com.br/arquivos/tipos.pdf> Acesso em: 12 mar. 2010.

PINHEIRO, Danielle da Silva. O bibliotecário e o atendimento aos usuários com necessidades especiais em unidades de informação. Revista de Iniciação Científica da FFC, Marília, v. 4, n. 3, 2004. Disponível em: <http//www.revistas.marilia.unesp. br>. Acesso em: 23 mar. 2010.

PRESSIONTT, Fernanda. Inclusão digital: cidadãos conectados. Disponível em <http:// www.unisys.com.br/premio2003/ inclusoodigital.htm>. Acesso em: 12 mai. 2010.

PROGRAMA Educação Inclusiva: direito à diversidade. Brasília: Ministério da Educação, 2004.

RODRIGUES, Andréa dos Santos; SOUZA FILHO, Guido Lemos de; BORGES, José Antônio. Acessibilidade na Internet para Deficientes Visuais. Disponível em: $<$ http://intervox.nce.ufrj.br/dosvox/textos/guido.doc>. Acesso em 31 jul. 2010

SASSAKI, Romeu Kazumi. Inclusão no lazer e turismo: em busca da qualidade de vida. São Paulo: Áurea, 2003.

VITAL, Marina Soares. A família e sua proteção aos direitos humanos internacionais. Disponível em: <http://www.jep.org.br/Downloads/MarinaVital.doc.>. Acesso em: 12 mar. 2010.

W3 CONSORTIUM. Web content accessibility guidelines 1.0: W3C Recommendation, 5 May 1999. 34 p. out. 2001.T-19990505. Disponível em: <http://www.w3.org/ TR/1999/WAI-WEBCONTEND>. Acesso em: 10 mar. 2010

W3C CONSORTIUM. Facts about W3C. Disponível em: <http://www.w3.org/ Consortium/facts\#history>. Acesso em: 10 mar. 2010.

WEB ACCESSIBILITY IN MIND (WEBAIM). Visual Disabilities: Low Vision. Disponível em: <http://www.webaim.org/articles/visual/ lowvision. php>. Acesso em: 10 mar. 2010. 
YIN, Robert K. Estudo de caso: planejamento e métodos. 2. ed. Porto Alegre: Bookman, 2001. 


\section{Para publicar na revista Universitas Gestão e TI, entre no endereço eletrônico www.publicacoesacademicas.uniceub.br. Observe as normas de publicação, facilitando e agilizando o trabalho de edição.}

